УДК 634.8

DOI 10.30679/2219-5335-2021-2-68-130-140

ФИЗИОЛОГИЧЕСКИЕ

ОСОБЕННОСТИ

КОРНЕСОБСТВЕННЫХ

ГИБРИДНЫХ ФОРМ ВИНОГРАДА

В ЛЕТНИЙ ПЕРИОД 1

Мишко Алиса Евгеньевна

канд. биол. наук

научный сотрудник

лаборатории физиологии

и биохимии растений

e-mail: mishko-alisa@mail.ru

Сундырева Мария Андреевна

канд. с.-х. наук

зав. лабораторией

физиологии и биохимии растений

e-mail: mari.sundy@bk.ru

Петров Валерий Семёнович

д-р с.-х. наук

руководитель научного направления, ведущий научный сотрудник

лаборатории управления

воспроизводством в ампелоценозах

и экосистемах

e-mail: petrov_53@mail.ru

Цику Дамир Муратович

аспирант, мл. научный сотрудник

лаборатории управления

воспроизводством в ампелоценозах

и экосистемах

e-mail:mr.tsiku@mail.ru

Марморштейн Анна Александровна аспирант, мл. научный сотрудник

лаборатории управления

воспроизводством в ампелоценозах

и экосистемах

e-mail: am342@yandex.ru
UDC 634.8

DOI 10.30679/2219-5335-2021-2-68-130-140

PHYSIOLOGICAL

FEATURES

OF NEW SELF-ROOTED

GRAPE HYBRID FORMS

IN SUMMER PERIOD ${ }^{1}$

Mishko Alisa Evgenievna

Cand. Biol. Sci.

Research Associate

of Plants Physiology

and Biochemistry of Laboratory

e-mail: mishko-alisa@mail.ru

Sundyreva Maria Andreyevna

Cand. Sci. Agr

Head of Plant Physiology

and Biochemistry Laboratory

e-mail: mari.sundy@bk.ru

Petrov Valeriy Semionovich

Dr. Sci. Agr.

Head of Scientific Direction,

Leading Research Associate

of Reproduction Control

in the Ampelocenoses

and Ecological Systems Laboratory

e-mail:petrov_53@mail.ru

Tsiku Damir Muratovich

Postgraduate, Junior Research Associate of Reproduction Control

in the Ampelocenoses

and Ecological Systems Laboratory

e-mail: mr.tsiku@mail.ru

Marmorshtein Anna Aleksandrovna

Postgraduate, Junior Research Associate

of Reproduction Control

in the Ampelocenoses and Ecological

Systems Laboratory

e-mail: am342@yandex.ru

\footnotetext{
${ }^{1}$ Исследование выполнено при финансовой поддержке РФФИ в рамках научного проекта № 20-316-90019

1 This research was carried out with financial support of the Russian Foundation for Basic Research within the framework of the scientific project № 20-316-90019
} 
Федеральное государственное бюджетное научное учреждение «Северо-Кавказский федеральный научный центр садоводства, виноградарства, виноделия», Краснодар, Россия

В работе представлены результаты оценки физиологического состояния новых корнесобственных гибридных форм столового винограда Акелло, Артек, Валенсия и Кураж, произрастающих на территории Краснодарского края в летний период. Контроль - устойчивый сорт Ливия отечественной селекции. Искусственная засуха смоделирована в лабораторных условиях. После стрессового воздействия были проанализированы следующие физиологические параметры листа винограда - степень повреждения клеточных мембран (по содержанию малонового диальдегида - одного окисления липидов клеточных мембран), относительное содержание воды, квантовый выход фотохимической реакции фотосистемы II, содержание хлорофилла $a$, соотношение хлорофиллов $a / b$. Установлено, что наиболее угнетающим месяцем для исследованных растений винограда был июль. Об этом свидетельствуют усредненные показатели всех исследованных сортов винограда по анализируемым параметрам - низкие значения фотосинтеза и относительного содержания воды в листьях и повышенный уровень малонового диальдегида, который определяет интенсивность развития окислительных процессов под влиянием неблагоприятных факторов. Наибольший адаптационный потенциал в данный период был выявлен у гибрида Артек, который имел высокие показатели фотосинтеза и низкое содержание малонового диальдегида. В августе для гибридных форм Артек и Кураж было характерно высокое относительное содержание воды в листьях и низкое - малонового диальдегида, причем уровень флуоресценции хлорофилла $a$ (квантовый выход) не изменился по сравнению с июлем. Гибрид Валенсия имел самые высокие значения малонового

\section{Federal State Budget}

Scientific Institution

«North Caucasian Federal

Scientific Center of Horticulture, Viticulture, Wine-making», Krasnodar, Russia

The article presents the results of assessing the physiological state of new self-rooted hybrid forms of table grape Akello, Artek, Valencia and Courage growing in the Krasnodar Territory in the summer period.

The cultivar Livia of Russian selection was selected as a control. Artificial drought was simulated in a laboratory conditionS. After stress effect, the following physiological parameters of grape leaves were analyzed the degree of damage to cell membranes (based on the content of malondialdehyde, one of the products of lipid peroxidation of cell membranes), the relative water content, the quantum yield of the photochemical reaction of photosystem II, the content of chlorophyll $a$ and the ratio of $a / b$ chlorophylls. It was found that the most depressed month for the studied grape plants was July. This is evidenced by the averaged indicators of studied grape plants according to the analyzed parameters low values of photosynthesis and relative water content in the leaves and increased level of malondialdehyde, which determines the intensity of the development of oxidative processes by the influence of negative factors. The greatest adaptive potential in this month was revealed in the Artek hybrid form, which had high value of photosynthesis and a low level of malondialdehyde content. In August, the hybrid forms of Artek and Courage were characterized by high values of the relative water content in the leaves and low value of malondialdehyde, and besides the level of chlorophyll $a$ fluorescence (quantum yield) did not change compared to July. The hybrid Valencia form had the highest value of malondialdehyde 
Плодоводство и виноградарство Юга России № 68(2), 2021 г.

диальдгида и низкие показатели относительного содержания воды в течение летнего периода, что позволяет определить его, как наименее устойчивую форму среди исследованных. Форма Артек выделена как наиболее устойчивая к воздействию стрессоров летнего периода на территории Краснодарского края, которая в дальнейшем может быть рекомендована для создания стабильных ампелоценозов.

Ключевые слова: ВИНОГРАД, ГИБРИДНАЯ ФОРМА, МАЛОНОВЫЙ ДИАЛЬДЕГИД, ОТНОСИТЕЛЬНОЕ СОДЕРЖАНИЕ ВОДЫ, ХЛОРОФИЛЛ and the lowest value of relative water content during the summer period, which makes it the least resistant form among the studied. The hybrid form of Artek was identified as the most resistant form to influence of summer stress factors in the territory of Krasnodar region. Further, this form can be recommend for the creation of stable ampelocenoses.

Key words: GRAPES, HIBRID FORMS, MALONDIALDEHYDE, RELATIVE WATER CONTENT, CHLOROPHYLL

Введение. Для создания устойчивых ампелоценозов следует учитывать большой перечень факторов. Это не только абиотические параметры среды обитания и уровень патогенной нагрузки, но и толерантность или восприимчивость самого сорта винограда к неблагоприятным воздействиям в конкретной области произрастания. На территории Краснодарского края главными абиотическими стрессорами летнего периода для винограда являются высокие температуры воздуха и дефицит влаги (засуха). Проявление адаптивных способностей к этим негативным воздействиям позволяет включать определенные сорта в перечень наиболее перспективных для данного региона. Причем все чаще преимущество остается за сортами отечественной селекции, адаптационный потенциал которых, как правило, оказывается выше интродуцированных сортов [1].

Одной из важных характеристик для определения устойчивости сортов винограда является культура ведения насаждений - привитая или корнесобственная. Как известно, корнесобственные растения европейских сортов Vitis vinifera L. крайне восприимчивы к филлоксере Daktulosphaira vitifoliae Fitch. C момента создания устойчивых к филлоксере подвоев американских видов винограда площади насаждений, зараженных филлоксерой, значительно сократились $[2,3]$. Кроме того, в некоторых работах отмечается способность американских подвоев под действием засухи сохранять высокий 
Плодоводство и виноградарство Юга России № 68(2), 2021 г.

уровень выживаемости по сравнению с корнесобственными за счет активации защитных механизмов - повышение активности антиоксидантых ферментов при пониженном водном потенциале [4]. Другими исследователями отмечено, что корнесобственные растения при отсутствии патогенного насекомого обладают достаточно высоким адаптационным потенциалом при воздействии абиотических стрессоров, таких как засуха и засоление [5-7].

В ответ на негативное влияние абиотических факторов среды летнего периода у винограда запускается целый ряд физиологических процессов. При высокотемпературном стрессе происходит снижение фотосинтетической активности, изменяется водный режим, а также развивается окислительный стресс, при котором идет накопление активных форм кислорода [8-11]. В условиях дефицита воды прежде всего нарушается газообмен в клетках растения, приводящий к изменению метаболизма (фотосинтеза, дыхания, транспирации), запускается синтез гормонов - в первую очередь абсцизовой кислоты, регулирующей закрытие устьиц $[12,13]$.

Среди защитных функций при дефиците влаги выделяют повышение содержания пролина и растворимых сахаров, а также рост активности антиоксидантных ферментов - супероксиддисмутазы, пероксидазы и каталазы [14]. Способность некоторых генотипов сохранять оптимальные значения этих параметров позволяет считать их более устойчивыми.

Таким образом отбор привитых и корнесобственных новых форм или сортов винограда необходимо осуществлять, опираясь на их адаптационный потенциал, который может быть различен и зависит от ряда составляющих.

Целью настоящего исследования является изучение физиологических параметров корнесобственных новых гибридных форм столового винограда и выявление среди них наиболее устойчивых к летним абиотическим стрессорам для формирования стабильных ампелоценозов. 
Объекты и методы исследований. Были изучены четыре новые корнесобственные гибридные формы столового винограда селекции С.Э. Гусева, произрастающие на территории КФХ «Фисюра» с. Красносельское Динского района Краснодарского края (45¹5'47"N 39011'33"Е). В качестве контрольного сорта использовали устойчивый сорт Ливия [15]. Растения подвергали высушиванию в лабораторных условиях путем помещения листовых дисков диаметром 1 см на сухую фильтровальную бумагу в закрытые чашки Петри на 2 часа при температуре $24-26^{\circ} \mathrm{C}$.

Для оценки степени повреждения клеточных мембран под влиянием искусственной засухи определяли содержание малонового диальдегида (MDA), который является одним из конечных продуктов перекисного окисления липидов [16]. Относительное содержание воды (RWC) в листьях винограда устанавливали по общепринятой методике [17]. Изменение активности фотосинтеза под воздействием стрессового фактора определяли по квантовому выходу (QY) фотохимической реакции фотосистемы II, а также по содержанию хлорофилла $a(\mathrm{Chl} a)$ и соотношению хлорофиллов $a / b(\mathrm{Chl} a / b)$. Квантовый выход измеряли с помощью РАМ-флуориметра [18]. Содержание хлорофиллов определяли спектрофотометрическим методом [19].

Данные представлены в виде средних значений, полученных в 2-3 биологических повторностях, и их стандартных ошибок для QY или стандартных отклонений для $\mathrm{Chl} a, \mathrm{Chl} a / b, \mathrm{MDA}, \mathrm{RWC}$. Степень достоверного различия значений определяли по непараметрическому критерию для малых выборок Колмогорова-Смирнова.

Обсуждение результатов. Содержание MDA, по сравнению с контрольным сортом Ливия (0,23 мМ/г сыр. массы), в июле у всех исследованных гибридов винограда возросло на 47-63\% и составило более 0,4 мМ/г сырой массы (рис. 1). В августе показатели данного параметра значительно 
снизились. Наименее выраженные окислительные процессы в условиях искусственной засухи наблюдались у гибридных форм Акелло, Артек и Кураж. Их значения были ниже контроля, что свидетельствовало о низком уровне повреждения клеточных мембран. У гибрида Валенсия образование малонового диальдегида в 1,25 раз превысило таковое у контрольного сорта.

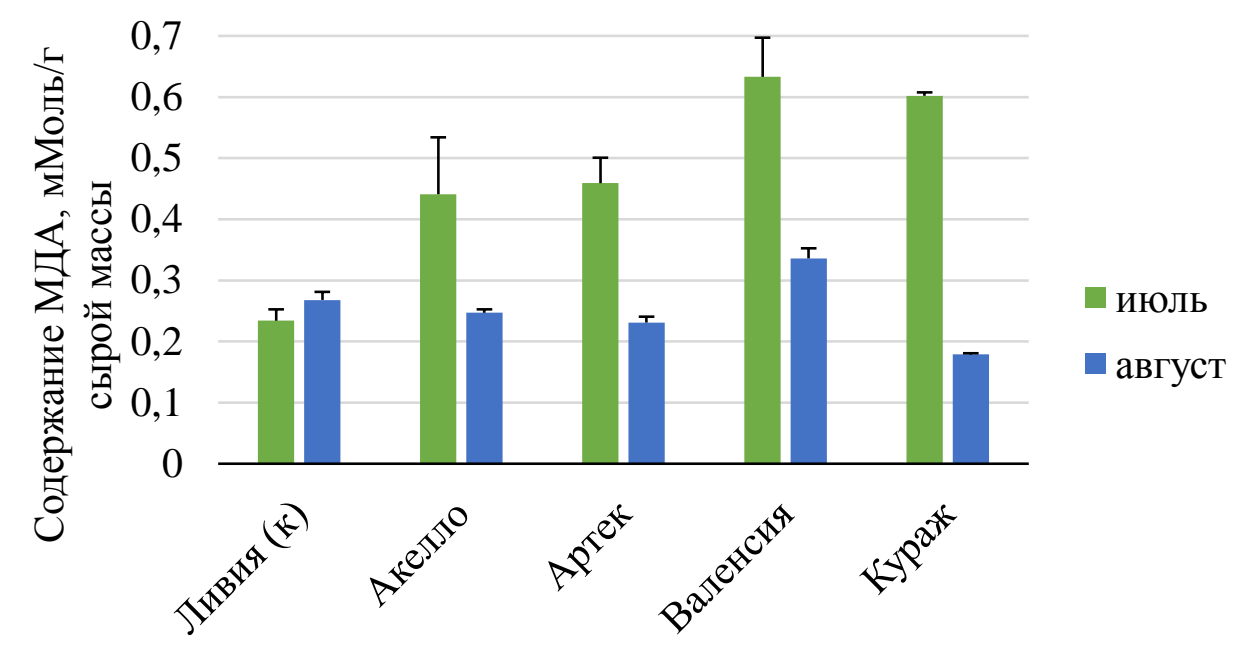

Рис. 1. Содержание малонового диальдегида в листьях винограда

Относительное содержание воды в листьях гибридных форм винограда в июле в среднем составило около 81 \%, в то время как у контрольного сорта Ливия этот показатель не превысил 79 \% (рис. 2). За этот период максимальные значения RWC были выявлены у гибрида Акелло ( $85 \%)$. В августе относительное содержание воды в листьях гибридов в среднем возросло до 82 \% так же, как и у сорта Ливия. Самые низкие значения данного показателя были у гибридной формы Валенсия (79 \%), а высокие - у гибрида Кураж (85 \%).

Засуха способствует закрытию устьиц, что является первоначальной причиной снижения фотосинтетической активности растений. Квантовый выход (QY) фотохимической реакции в ФС II отражает эффективность использования ФАР растением. Стрессовые условия приводят к понижению этого показателя у неустойчивых растений [20]. 
Проведенные лабораторные исследования показали, что у всех гибридных форм в летний период квантовый выход фотосинтеза составил более 0,7 , что соответствует нормально функционирующему фотосинтетическому аппарату (рис. 3). В июле, после высушивания, у гибридов Акелло и Артек значение QY было выше, чем у контроля, а у гибридных форм Валенсия и Кураж, напротив, ниже. В августе показатели гибрида Акелло снизились на $6 \%$, у гибрида Валенсия повысились на $5 \%$. Значения квантового выхода гибридных форм Артек и Кураж остались на том же уровне - 0,77 и 0,75 соответственно.

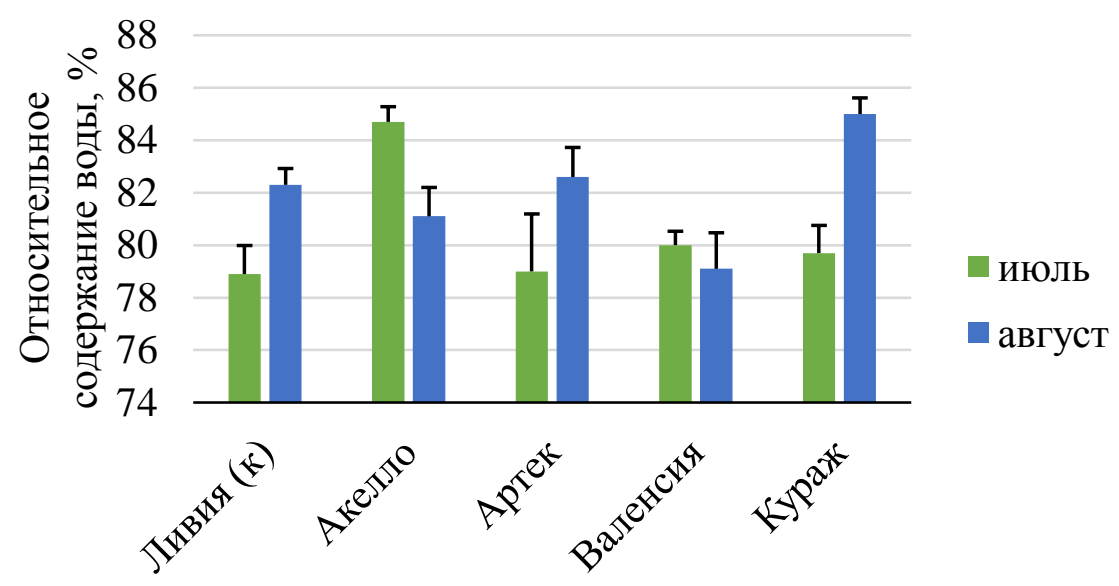

Рис. 2. Относительное содержание воды в листьях винограда

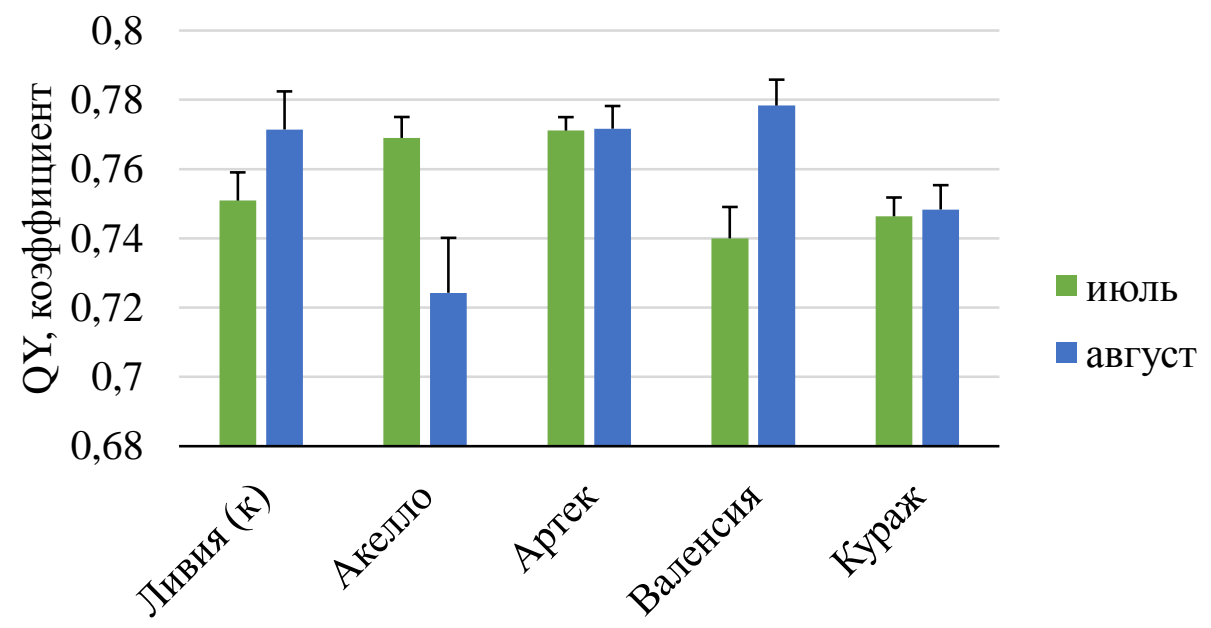

Рис. 3. Квантовый выход фотосинтеза у листьев винограда 
По содержанию хлорофилла $a$ максимальные значения, близкие к показателям контрольного сорта Ливия, были выявлены в июле у гибрида Артек, в августе - у гибрида Валенсия (рис. 4). В среднем показатели за август у исследованных гибридных форм возросли по сравнению с июлем, в том числе и значения контрольного сорта. Исключение составил гибрид Артек, значения Chl $a$ которого упали на $\sim 13 \%$.

Соотношение $\mathrm{Chl} a / b$ в июле было максимальным у гибрида Валенсия на фоне низкого показателя $\mathrm{Chl} a$, минимальным - у гибрида Кураж (см. рис. 4). В августе значения данных параметров у всех изученных гибридных форм винограда незначительно превышали контроль.

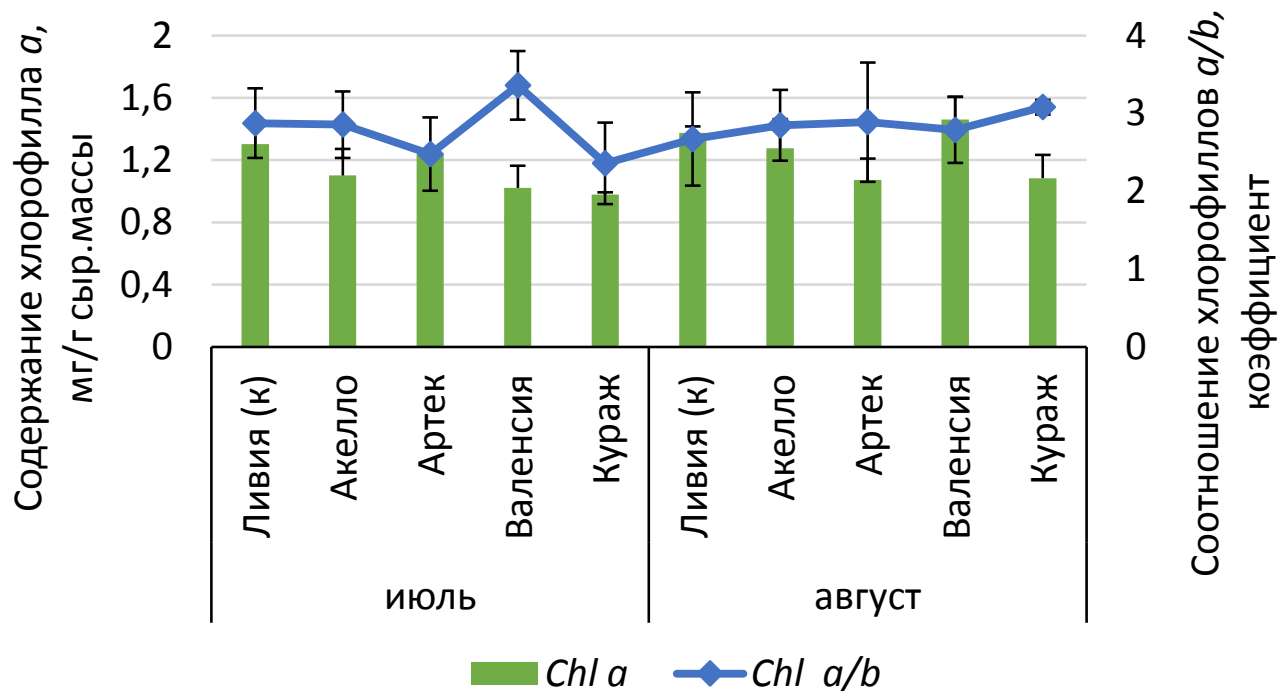

Рис. 4. Содержание хлорофилла $a$ и соотношение хлорофиллов $a / b$ в листьях винограда

Bbыводы. Согласно представленным данным можно заключить, что ответная реакция гибридных форм винограда на воздействие искусственной засухи была более ярко выражена в августе, чем в июле. Об этом свидетельствуют низкое содержание малонового диальдегида в листьях, маркера окислительного стресса, и высокие значения Chl $a$ и RWC, отражающие нормальное протекание физиологических процессов. При этом в более стрессовый месяц (июль) больший уровень устойчивости показали 
две гибридные формы - Артек и Акелло, содержание MDA у которых было ниже, чем у гибридов Валенсия и Кураж. Артек отличился высоким уровнем фотосинтеза по показателям QY и Chl $a$. Гибрид Акелло имел максимальные значения RWC.

В августе для гибридных форм Артек и Кураж были характерны высокие значения RWC и низкие показатели MDA, причем уровень QY не изменился по сравнению с июлем. Гибрид Валенсия имел самые высокие значения MDA и низкие - RWC, что позволяет определить его как наименее устойчивую форму.

Таким образом, по результатам представленных исследований наиболее перспективной корнесобственной гибридной формой винограда является Артек, который показал высокий адаптационный потенциал в течение всего изученного периода. Остальные изучаемые гибриды характеризуются вариабельностью физиологических параметров, среди них наименьший уровень устойчивости выявлен у гибридов Кураж и Валенсия.

\section{Литература}

1. Полулях А.А., Волынкин В.А. Генетические ресурсы винограда для интродукции и селекции // Виноградарство и виноделие. 2020. Т. 49. С. 83-86.

2. Granett, J., M. A. Walker, L. Kocsis, and A. D. Omer. 2001a. Biology and management of grape phylloxera. Annu. Rev. Entomol. V. 46. P. 387-412.

3. Ollat N., Peccoux A., Papura D., Esmenjaud D., Marguerit E., Tandonnet J., Bordenave L., Cookson S., Barrieu F., Rossdeutsch L. Rootstocks as a component of adaptation to environment / H. Gerós, M.M. Chaves, H.M. Gil, S. Delrot (Eds.). West Sussex, UK: WileyBlackwell, 2016. Ch.4. P. 68-108.

4. Sucu S., Yagci A., Yildirim K. Changes in morphological, physiological traits and enzyme activity of grafted and ungrafted grapevine rootstocks under drought stress // ErwerbsObstbau, 2018. V. 60. P. 127-136.

5.Tahanian H.R., Ebadi A., Salami A.R. Effect of rootstocks on physiological and biochemical responses of Vitis vinifera 'Shahroudi' to salinity and bicarbonate stress conditions // Iranian Journal of Horticultural Science and Technology, 2019. V. 20(1). P. 1-10.

6. Azri1 W., Cosette P., Guillou C., Rabhi M., Nasr Z., Mliki A. Physiological and proteomic responses to drought stress in leaves of two wild grapevines (Vitis sylvestris): a comparative study // Plant Growth Regulation. 2020. V. 91. P. 37-52.

7. Chrysargyris A., Xylia P., Litskas V., Stavrinides M., Heyman L., Demeestere K., Hofte M., Tzortzakis N. Assessing the impact of drought stress and soil cultivation in Chardonnay and Xynisteri grape cultivars // Agronomy. 2020. V. 10. P. 670. 
8. Wang L-J., Fan L., Loescher W., Duan W., Liu G.-J., Cheng J.-S., Luo H.-B., Li S.-H. Salicylic acid alleviates decreases in photosynthesis under heat stress and accelerates recovery in grapevine leaves // BMC Plant Biology. 2010. V.10. P. 34.

9. Carvalho L.C., Coito J.L., Gonçalves E.F., Chaves M.M., Amancio S. Differential physiological response of the grapevine varieties Touriga Nacional and Trincadeira to combined heat, drought and light stresses. Plant Biology. 2016. V. 18. P. 101-111.

10. Jiang J., Liu X., Liu Ch., Liu G., Li Sh., Wang L. Integrating omics and alternative splicing reveals insights into grape response to high temperature // Plant Physiology. 2017. V. 173. P. 1502-1518.

11. Zha Q, Xi X, He Y, Jiang A Comprehensive evaluation of heat resistance in 68 Vitis germplasm resources // Vitis. 2018. V. 57. P. 75-81.

12. Patakas A., Noitsakis B., Chouzouri A. Optimization of irrigation water use in grapevines using the relationship between transpiration and plant water status // Agriculture, Ecosystems and Environment. 2005. V. 106. P. 253-259.

13. Chen L., Jun A.I., Wang Z.X., Zhao Y. Research progress on effect of drought stress on the physiological property and microstructure in grapevine // North. Hortic. 2011. V. 6. P. 205-209.

14. Haider M.S., Zhang C., Kurjogi M.M., Pervaiz T., Zheng T., Zhang C., Lide C., Shangguan L., Fang J. Insights into grapevine defense response against drought as revealed by biochemical, physiological and RNA-Seq analysis // Scientific Reports. 2017. V. 7. P. 13134.

15. Бейбулатов М.Р., Тихомирова Н.А. Развитие столового виноградарства на южном берегу Крыма // «Магарач». Виноградарство и виноделие. 2013. № 1. С. 2-3.

16. Молекулярно-генетические и биохимические методы в современной биологии растений / под ред. Вл.В. Кузнецова, В.В. Кузнецова, Г.А. Романова. М.: БИНОМ. Лаб. знаний, 2012. 487 с.

17. Filella I., Llusia J., Pinol J., Penuelas J. Leaf gas exchange and fluorescence of Phillyrea latifolia, Pistacia lentiscus and Quercus ilex saplings in severe drought and high temperature conditions // Environmental and Experimental Botany. 1998. V. 39. P. 213-220.

18. Переменная и замедленная флуоресценция хлорофилла а - теоретические основы и практическое приложение в исследовании растений / В.Н. Гольцев [и др.]. М. Ижевск: Институт компьютерных исследований, 2014. 220 с.

19. Lichtenthaler H.K., Buschmann C. Extraction of photosynthetic tissues: chlorophylls and carotenoids // Current Protocols in Food Analytical Chemistry. 2001. F4.2.1-F4.2.6.

20. Wang Z.X., Chen L., Ai J., Qin H.Y., Liu Y.X., Xu P.L., Jiao Z.Q., Zhao Y., Zhang Q.T. Photosynthesis and activity of photosystem II in response to drought stress in Amur Grape (Vitis amurensis Rupr.) // Photosynthetica. 2012. V. 50(2). P. 189-196.

\section{References}

1. Polulyah A.A., Volynkin V.A. Geneticheskie resursy vinograda dlya introdukcii i selekcii // Vinogradarstvo i vinodelie. 2020. T. 49. S. 83-86.

2. Granett, J., M. A. Walker, L. Kocsis, and A. D. Omer. 2001a. Biology and management of grape phylloxera. Annu. Rev. Entomol. V. 46. P. 387-412.

3. Ollat N., Peccoux A., Papura D., Esmenjaud D., Marguerit E., Tandonnet J., Bordenave L., Cookson S., Barrieu F., Rossdeutsch L. Rootstocks as a component of adaptation to environment / H. Gerós, M.M. Chaves, H.M. Gil, S. Delrot (Eds.). West Sussex, UK: WileyBlackwell, 2016. Ch.4. P. 68-108.

4. Sucu S., Yagci A., Yildirim K. Changes in morphological, physiological traits and enzyme activity of grafted and ungrafted grapevine root-stocks under drought stress // ErwerbsObstbau, 2018. V. 60. P. 127-136. 
5.Tahanian H.R., Ebadi A., Salami A.R. Effect of rootstocks on physiological and biochemical responses of Vitis vinifera 'Shahroudi' to salinity and bicarbonate stress conditions // Iranian Journal of Horticultural Science and Technology, 2019. V. 20(1). P. 1-10.

6. Azri1 W., Cosette P., Guillou C., Rabhi M., Nasr Z., Mliki A. Physiological and proteomic responses to drought stress in leaves of two wild grapevines (Vitis sylvestris): a comparative study // Plant Growth Regulation. 2020. V. 91. P. 37-52.

7. Chrysargyris A., Xylia P., Litskas V., Stavrinides M., Heyman L., Demeestere K., Hofte M., Tzortzakis N. Assessing the impact of drought stress and soil cultivation in Chardonnay and Xynisteri grape cultivars // Agronomy. 2020. V. 10. P. 670.

8. Wang L-J., Fan L., Loescher W., Duan W., Liu G.-J., Cheng J.-S., Luo H.-B., Li S.-H. Salicylic acid alleviates decreases in photosynthesis under heat stress and accelerates recovery in grapevine leaves // BMC Plant Biology. 2010. V.10. P. 34.

9. Carvalho L.C., Coito J.L., Gonçalves E.F., Chaves M.M., Amancio S. Differential physiological response of the grapevine varieties Touriga Nacional and Trincadeira to combined heat, drought and light stresses. Plant Biology. 2016. V. 18. P. 101-111.

10. Jiang J., Liu X., Liu Ch., Liu G., Li Sh., Wang L. Integrating omics and alternative splicing reveals insights into grape response to high temperature // Plant Physiology. 2017. V. 173. P. 1502-1518.

11. Zha Q, Xi X, He Y, Jiang A Comprehensive evaluation of heat resistance in 68 Vitis germplasm resources // Vitis. 2018. V. 57. P. 75-81.

12. Patakas A., Noitsakis B., Chouzouri A. Optimization of irrigation water use in grapevines using the relationship between transpiration and plant water status // Agriculture, Ecosystems and Environment. 2005. V. 106. P. 253-259.

13. Chen L., Jun A.I., Wang Z.X., Zhao Y. Research progress on effect of drought stress on the physiological property and microstructure in grape-vine // North. Hortic. 2011. V. 6. P. 205-209.

14. Haider M.S., Zhang C., Kurjogi M.M., Pervaiz T., Zheng T., Zhang C., Lide C., Shangguan L., Fang J. Insights into grapevine defense response against drought as revealed by biochemical, physiological and RNA-Seq analysis // Scientific Reports. 2017. V. 7. P. 13134.

15. Bejbulatov M.R., Tihomirova N.A. Razvitie stolovogo vinogradarstva na yuzhnom beregu Kryma // «Magarach». Vinogradarstvo i vinodelie. 2013. № 1. S. 2-3.

16. Molekulyarno-geneticheskie i biohimicheskie metody v sovremennoj biologii rastenij / pod red. Vl.V. Kuznecova, V.V. Kuznecova, G.A. Romanova. M.: BINOM. Lab. znanij, 2012. $487 \mathrm{~s}$.

17. Filella I., Llusia J., Pinol J., Penuelas J. Leaf gas exchange and fluorescence of Phillyrea latifolia, Pistacia lentiscus and Quercus ilex saplings in severe drought and high temperature conditions // Environmental and Experimental Botany. 1998. V. 39. P. 213-220.

18. Peremennaya i zamedlennaya fluorescenciya hlorofilla a - teoreticheskie osnovy i prakticheskoe prilozhenie v issledovanii rastenij / V. N. Gol'cev [i dr.]. M.-Izhevsk: Institut komp'yuternyh issledovanij, 2014. $220 \mathrm{~s}$.

19. Lichtenthaler H.K., Buschmann C. Extraction of photosynthetic tissues: chlorophylls and carotenoids // Current Protocols in Food Analytical Chemistry. 2001. F4.2.1-F4.2.6.

20. Wang Z.X., Chen L., Ai J., Qin H.Y., Liu Y.X., Xu P.L., Jiao Z.Q., Zhao Y., Zhang Q.T. Photosynthesis and activity of photosystem II in response to drought stress in Amur Grape (Vitis amurensis Rupr.) // Photosynthetica. 2012. V. 50(2). P. 189-196. 